\title{
An article on explosion of ethnic violence in Warrap state In south Sudan
}

\author{
Article by Emmanuel Moju, \\ MSC on clinical psychology, Texila American University, South Sudan \\ Email:moju.andrea2015@gmail.com
}

\begin{abstract}
As matter of facts, ethnic conflict is an outcome of number of interrelated factors. It is important to cautiously and thoroughly study each of these factors and establish relationship among the characteristics involved. Appropriate approach is useful in an endeavor to resolve ethnic conflicts through a peaceful means.

Ethnic conflict leads, among other things, to the breakdown of law and order, the disruption of economic activities, political stability, humanitarian crises and a state of uncertainty which prevent long run investment and development efforts and peace. A case on line is the conflict that broke out between the SPLA and SPLA in opposition on 15th December 2013, in South Sudan, all the developments made from independence till the date were gone.

Violent ethnic conflict leads to extraordinary displacement of people including vulnerable groups such as women, children, the elderly as well as the disabled who often are seriously affected by violent conflict. Therefore, it is worthwhile to give due concern to interethnic relations and manage it cautiously and systematically. Conflict is like contagious disease. Unwise handling of conflict gives it the opportunity to widespread all of a sudden. If it occurred, conflict must be handled at its early stages. Once allowed to escalate, it would change to violence that cannot be easily remedied and control. A good example is the Central Africa Republic ongoing ethnic violence between the Muslims and the Christians (Alemayehu, Fantaw. (2009).

Key Words :The key words in this article are: Dinka, Nuer Jurchol, Bongo and ethnic violence

\section{Background of the study area}

Warrap State population is dominantly Dinka; it enjoys relative ethnic homogeneity, with exception of the southern part of the state which is occupied by the Jur Chol and the Bongo tribes. It is largely rural society with $98 \%$ of the population engaged in animal husbandry and crop farming for livelihoods (Deng, Francis M. 1978).

The Dinka tribe is the biggest tribe in South Sudan; followed by Nuer tribe, they occupy south central Sudan along the White Nile River and its tributaries, from Renk in the north to Bor in the south and from Bor in the East to Aweil in the west (Deng, Francis M. 1978).

This study which focused on ethnic conflicts among the Dinkas communities of Warrap state will critically scrutinized the cultural beliefs as source of ethnic conflicts. Most significantly the study will explore the various cultural beliefs and how they bring about ethnic conflict and its impact on the social and economic development in Warrap state. The study also sought to identify probable conflict transformation mechanisms to enhance peaceful co-existence among these pastoral communities (Galtung 1996).

Both primary and secondary data was collected to compile the article, it was paramount to collect information from both sources, because Warrap state does not have library neither archive comprehensive enough to obtain the required information.
\end{abstract}


South American Journal of Academic Research

Special Edition May 2016

\section{The purpose}

Warrap state is deliberately chosen for this study due to its high ethnic violence, spouse battering and capital punishments.

\section{Critical review}

\subsection{Impact of the war in south sudan}

Ethnic conflict can play a crucial role, both in the collapse of the central government; and at the extreme cases, the disintegration of the country totally, as the case with the current escalation of ethnic conflict in Somalia and South Sudan.

Looking from economic point of view, ethnic conflict destroys the very bases of development: environmental resources, economic, infrastructure, and the social and civic ties that permit and sustain development. The total breakdown of the country's infrastructure and other economic resources in South Sudan can be taken as good examples. When there is violent conflict in a country, resources that otherwise could have been invested for development activities, would be shifted to cover the expense of the war. The industrious labor force will be drained to the war front and hence production and productivity decline in the countries engaged in the war. In a country where there is violent conflict no investors would like to invest, and therefore no job opportunities created for the people. Trade and other social and civil institutions either completely or partially cease their services as a result of which life become costly and terrible. Conflict is a major factor of vulnerability that destroys people's social and private property and trigger unemployment in the area. Agriculture activities ceases, famine creep in, looting and high mortality due to malnutrition sours high the nation is weaken (Shibru D, 2009 p24).

\subsection{Social and economic status of warrap state people}

The main source of livelihood is Cattle; these animals form the basis of Dinka livelihood, religion, and social structure. The importance of cattle in the Dinka economy has had great influence in the politics of contact between the Dinka and other pastoral and non-pastoral communities in South Sudan. This contact was initially based on exchange, but has gradually developed into hostility, as Dankas herding, they desire their neighbors cattle and their neighbor desire Dink's cattle too. The non - pastoral community were inconvenient because the cattle sometimes eat food crops of the peasants resulting into fights, famines and environmental degradation due to over grazing. Cattle have been both directly and indirectly a major cause of the rise of conflicts in the region as they represent social, cultural, and economic security of the Dinka community (Deng, Francis M. 1978).

\subsection{Structural violence}

This article introduces the concept of cultural violence and can be viewed as trajectory to better understanding of structural violence in mostly rural society in Warrap State. South Sudan community has witnessed a sharp increase of ethnic violence in Greater Bahr el Ghazal including Warrap State over the last 2 years. Other people attributed the increase of violence to the dwindling economy and poverty and war. Other people think the cause of the ethnic violence is the existing culture of violence among the community of Bahr el Ghazal and especially Warrap State. This article was developed to provide readers with better understanding of interaction between War, Culture, and poor law enforcement, promotion of impunity, marginalization and macho man. The availability and existence of these factors in the country was considered as

precipitating factors to the current structural violence. Violence is defined here as any aspect of a culture that can be used to legitimize violence in its direct or structural form. In this article, cultural violence is viewed as used to legitimize both negative and positive social practices in a community. 


\subsection{The context of violence in warrap state}

In the context of South Sudan, the cultural violence in Warrap State is protected under the premise of security to animals and properties from neighboring tribes, but to the contrary, the same community does raid cattle among themselves creating vicious circle of violence within the same community and this was seen in Warrp state where this study was undertaken.

The consideration of culture as a major factor in the ethnic violence and spoiler of peaceful coexistence within diverse communities in Warrap State is a land mark for quest of better strategies to establish peaceful coexistence among the cattle keeper.

The study aim at generating possible tangible strategies to curb the level of violence among communities in Warrp state and if appropriate extended to other states in greater Bahr el Ghazal where similar violence is ongoing.

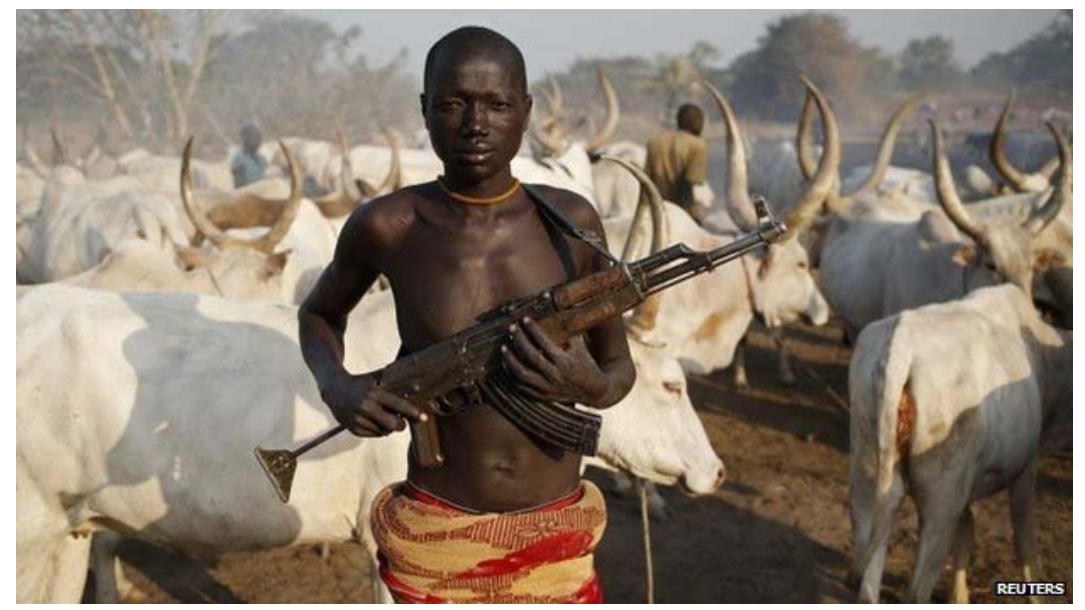

Image adopted from: https://www.google.com/search?q=cattle+raiding+in+jonglei\&tbm

Warrap state is one of the states affected with ethnic violence, un-justified killings, spouse battering and capital punishment is rampant.

The scope of the study was constrained by financial limitation of the investigator; the study could have been expanded to cover the greater Bahr el Ghazal states which are equally heavily affected by the current ongoing ethnic violence. However within the current confine of the study, fascinating facts have been obtained which suggest weakness in the current national structures as well as the governing machineries available for the welfare of the South Sudanese communities as the contributing factors to the escalation of the violence.

\subsection{Law enforcement}

Interaction with the respondents $21 \%$ revealed that, people who were killed on the street, in their homes, during cattle raiding are victims of poor law enforcement in the country. They argue that the criminals were not caught because they either have relatives who are very senior in the government or feared that their community will seek revenge on the policeman who arrest him. Others argue that criminals are deliberately released from dungeon without punishment through intervention of their senior relatives in the government.

\subsection{The customary law of compensation for killing}

The respondents 3\% argue that payment of huge amount of cattle to compensate for killing is another causative factor for violence; firstly, the cows for compensation of the death person are contributed by the relatives of the killer, which makes it easier for the criminal to obtain the cows with less difficulty. Secondly, the acceptance by the relative to contribute cattle to compensate the relatives of the assassinated person is a clear promotion of impunity which breed structural 
South American Journal of Academic Research

Special Edition May 2016

violence. Thirdly, due to such practice, it has become easier to practice the culture of revenge killing as long as the relatives are willing to pay for the killing. Finally, the government within the current scope of extra judicial killing has accepted the traditional laws of compensation of victims without additional conditions/punishment that could make the killers feel the negative effect of taking the law into their hands.

\subsection{Arms Proliferation}

The respondents (31\%) stated that during the current war, many soldiers clandestinely quit their military jobs when asked to go to front line, because they quitted secretly, they kept their guns leading to increase of violence and robbery. Majority of participants concur with the above notion, they argue that $98 \%$ of killings done were with guns and this applies also to cattle raiding. One of the participants stated that nobody can attempt cattle raiding without possessing a gun.

During the focus group discussion, it came out clearly that other military personnel return from the frontlines with their weapons to stay with them at home leading to unnecessary killing, cattle raiding, robberies and social misconduct

Majority of respondents $70 \%$ argue that military personnel do not wish to leave their jobs because it is their source of livelihood, but the notion that the current war is tribalistic in nature have added into the defection out of the profession.

\subsection{Spouse battering}

In a focus group discussion, it came out that the increase of violence at home e.g. spouse battering and capital punishment could be attributed to the culture and behavior of Macho man, especially among soldiers and people who participated in the war. Most perpetrators of violence are former soldiers or people who have contributed in the movement in one way or another and have connection with senior officials in the government; therefore such individuals put themselves above the law.

\subsection{The attitude of impunity}

Almost $100 \%$ of the respondents concur that every person in South Sudan claim to be a soldier, and in every argument, they ask their opponent do you know who I am. Meaning he is a very senior officer in the army, police, wildlife, security and etc. and have the prerogative to kill you or do anything to you and will not be prosecuted. This concession is true because many criminals who have committed crimes in similar manner have either being left free or not arrested at all. This promoted the spirit of impunity among the organized forces in the country

The other argument which came out clearly is that, even those who are not in the army but have their relatives holding high positions in the government or in the army tend to take the law into their hands, because whatever crime they do, they are released from incarceration without prosecution. The Government machinery in places seems to favor such individuals and instead punish poor and low class individuals who do not have the capacity to help them self when brought before the court of law, and such poor individual become victims of the law without justices. 


\subsection{Arms in the hands of civilians}

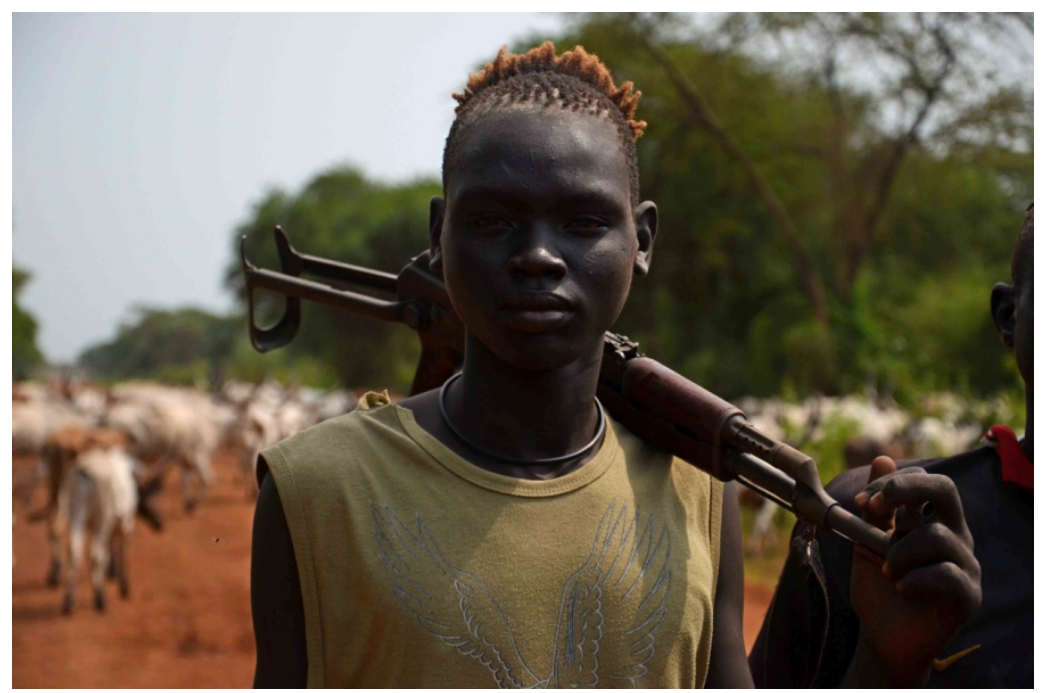

Image adopted from: https:/www.google.com/search?q=cattle+raiding+in+jonglei\&tbm

Others argue that the increase of violence in the state could partly be due to civilian's accessibility to guns, indeed in Warrap state, many civilians are openly carrying unauthorized weapon without being arrested. People wonder where such people get their arms and munitions. Respondents argue that if the weapon is illegal, then the government would have arrest them for possession of illegal weapons, but nobody has ever been arrested, meaning that it could be the government arming certain community illegally, either as militia or for some bad intentions.

\subsection{Causes of mob justices}

One of the areas potential for further investigation is the law enforcement in the state as well as in the entire nation, $2 \%$ of the participants argue that currently you cannot arrest a thief, because the police officers will first request for money to arrest the culprit and after paying money and the criminal is brought to the cell, the officers request you to feed the criminal or otherwise they will release the criminal without being prosecuted

According to the $2 \%$ participants, this act by the law enforcement body led to the circle of revenge attacks. Offended individuals simply belief that since they cannot get their rights through the legal and justice's center of the country, they better kill, punish or revenge directly.

Mob justice in many countries can be defined as people taking the law into their hands by killing or punishing members of the community who misbehaved e.g. stealing and etc. in South Sudan it is differently viewed, it posters itself in revenge attacks and killings, other respondents argue that the fact that no one still get his rights from the legal machinery of the government has increased the level of revenge attacks. They argue that many criminals are released without prosecution from incarceration. This encroached into the dignity of the accuser and his or her rights of being a citizen in the country where his or her property has been stolen.

\subsection{Psychological effects of the war}

Others argue that the level of violence witnessed in the state as well as in the country could be attributed to psychological effect of the war. Many believed that people are traumatized because others lost properties, lost their family member, lost their jobs and many more, but, because there is nowhere to ventilate the stress due to lack of psychiatry and counseling services in the country, they ended up being violent.

Eye witnesses confessed that majority of war victims saw their mothers, sisters or wives rape or parents killed. Yet such individuals are left without psychological care, they struggle on their 
South American Journal of Academic Research

Special Edition May 2016

own to recover from the trauma. Many believed such lack of psychological services contributed to the explosion of violence in Warrap state and other parts of the country (United Nations Mission in the Republic of South Sudan, May 8, 2014.).

\subsection{Youth education and Joblessness}

History shows that majority of people participating in violence acts are young adults and they are the majority who have been in the army. This is not by coincidence, because the biggest population of the country is young men and is actively participating in the ethnic violence.

The facts that majority of these population are jobless, it made them potential tools for the rich to utilize them execute their malicious aims

The respondents stated that majority of youth in Warrap are not educated, hence are easily exploited. They call for the government to establish vocational training centers where such youth can be trained on how to obtain their future livelihoods.

According to South Sudan bureau of statistics, 2009: Total Population of South Sudan is 8.26 million

- More than half (51\%) of the population is below the age of eighteen.

- $72 \%$ of the population is below the age of thirty

- $27 \%$ of the adult population is literate

In Warrap 91\% of its population live in rural areas compared to $83 \%$ in South Sudan as a whole. $16 \%$ of the 15 years and above population is literate. This increased to $27 \%$ for the age group 15-24 respectively (National Baseline Household Survey 2009).

Meaning that majority of youth in Warrap are not educated hence possibility of exploitation for malignant purposes.

Other respondents argue that unless education is made compulsory, parents and care takers are punished for not taking children to school, the level of violence will not reduce. They cry for new education polices and curriculum that are more relevant and practical to the current crises. It is the responsibility of the government to take care of the street children for development of skills and appropriate morals as future citizens of this country. Children who drop out of schools due to fees, stubbornness and etc. should be hunted and taken to vocational training centers where they can be remodel for better future benefit of the state (Jok, Jok Madut 1998).

\subsection{Culture and violence}

The fact that the culture in Warrap state is a polygamous culture where men are marrying 10 to 20 women even above, this culture pose real threat to perpetuating violence, because these families are incapable to care for their children, hence majority goes to the street seeking survival. On the other hand, because life out there is harsh forces them to delinquency, pocket picking and many more. Other participants cry that the government should intervene to stop such culture which first of all dehumanizes women as well as their children. Such culture deprives this vulnerable population of their rights to decent lives; therefore government should impose smaller families' police so that few or no children find their way to the street.

Women argue that it is this culture of polygamy that made men unable to care for their families; in terms of health, nutrition and education. Men leave their families to play cards and domino till evening bringing nothing home with the hope that if one wife did not cook the other will. They argue, if this culture is stopped a new down will arise where men take responsibility of their families and desire smaller families to enable better upbringing of children both educationally and socially.

The study also found that men who have married more than five women tend to leave their wives in the villages, go to the town and marry young girls to enjoy life, while the older wives are left in the villages without upkeep allowance to support their children. These frustrate children to leave their homes and go to towns seeking survival as street children. 
A woman too, having been abandoned seeks means of survival, others brew alcohol others engaged in prostitution leading to increased risk of contracting sexual transmission infection and distributing HIV. The act of abandoning women to the village is equal to psychological violence where the victim is tormented silently till she makes such negative decision to her own detriment.

\subsection{Conclusion}

The cause of increased ethnic violence in Warrap state can be attributed to horde of factors: political, socio-economic and cultural. Poor law enforcement is implicated in bringing about the vicious cycle of revenge killing. Others argue that promotion of impunity by the top ruling figures acted as precipitating factors for the ethnic conflict. People took the law into their hands because they see criminals left free without prosecution.

Availability of arms in the hands of civilians increased the level of violence and cattle raiding leading to unnecessary killings and looting

\subsection{Reference}

[1.] 5th Population and Housing Census (2008)

[2.] Alemayehu, Fantaw. (2009).Conflict Management in the Ethiopian Multi-national Federation European University, Center for peace studies (MA Thesis), Stadtschlaining.

[3.] Census Priority Results (2009)

[4.] Deng, Francis M. (1978). Tradition and Modernization: A Challenge for Law among the Dinka of Sudan. New Haven: Yale University Press.

[5.] http://www.br.de/radio/bayern2/sendungen/notizbuch/suedsudan-krieg-nationalstaat-100.html

[6.] https://www.google.com/search?q=cattle+raiding+in+jonglei\&tbm

[7.] Jok, Jok Madut (1998). Militarization, Gender and Reproductive Health in South Sudan. Lewiston, NY: Edwin Mellen Press.

[8.] Miraya FM, “Warrap State to Aid Return of Abyei Citizens,” July 31, 2013, http://reliefweb.int/report/south-sudan-republic/warrap-state-aid-return-abyei-citizens

[9.] Radio Tamazuj, “Hunger Among Displaced in Gogrial West,” July 15, 2014.

https://radiotamazuj.org/en/article/hunger-among-displaced-gogrial-west

[10.] Small Arms Survey, Human Baseline Assessment for Sudan and South Sudan

[11.] Southern Sudan Household Health Survey Report (2006)

[12.] Southern Sudan Livelihood Profiles (2008)

[13.] Statistical Yearbook for Southern Sudan (2009)

[14.] United Nations Mission in the Republic of South Sudan, Conflict in South Sudan: A Human Rights

Report, May 8, 2014. 